\title{
Wound healing complications in oncological patients: perspectives for cellular therapy
}

\author{
Milena Deptuła ${ }^{1}$, Jacek Zieliński², Anna Wardowska ${ }^{3}$, Michał Pikuła ${ }^{3}$ \\ 'Department of Embryology, Medical University of Gdansk, Gdansk, Poland \\ ${ }^{2}$ Department of Surgical Oncology, Medical University of Gdansk, Gdansk, Poland \\ ${ }^{3}$ Department of Clinical Immunology and Transplantology, Medical University of Gdansk, Gdansk, Poland
}

Adv Dermatol Allergol 2019; XXXVI (2): 139-146

DOI: https://doi.org/10.5114/ada.2018.72585

\begin{abstract}
Various types of cancer are nowadays a serious medical and social problem and a great challenge for modern medicine. The majority of anticancer therapy is based on traditional chemotherapy and radiotherapy. Both of these highly non-specific types of treatment have a number of serious side effects including wound healing complications. Radiotherapy and chemotherapy mostly affect rapidly dividing skin cells (e.g. keratinocytes), as well as fibroblasts, melanocytes, endothelial and immune cells. Currently, there are many strategies to improve wound healing in oncological patients, including various types of dressings, biomaterials, growth factors, and cell therapies.
\end{abstract}

Key words: wounds, cancers, cell therapy.

\section{Introduction}

Cancer diseases represent one of the largest and still increasing problems of modern medicine, with implications for economics and social aspects of civilization. They are also the cause of the majority of deaths in developed countries. The most common treatments of malignant neoplasms are radio- and chemotherapy. Therefore, their side effects are a vital issue and a great challenge to modern oncology. Among the most important adverse effects of radio- and chemotherapy are skin homeostasis disorders. There are approximately 14 million neoplasm cases diagnosed every year worldwide. About $30 \%$ of these patients are treated with chemo- or radiotherapy [1-3].

Chronic wounds can form as a result of radio- or chemotherapy themselves, both types of adjuvant therapies and even due to surgery itself. Both adjuvant therapies, radio- and chemotherapy, have a number of adverse effects with a systemic impact including skin disturbances. There is a constant search for an effective healing treatment, as well as tissue loss in oncological patients. Among the interesting methods are conventional wound dressings, biomaterials, growth factors and tissue engineering products based on in vitro cultured allogeneic or autologous cells [4].
The aim of the this review is to present the process of wound healing and possible complications in oncological patients subjected to adjuvant and/or neoadjuvant therapy. Additionally, we present an analysis of potential clinical application of new therapies with positive outcomes in wound healing.

\section{Wound healing - stages and critical factors}

There are three major overlapping stages in the process of wound healing: inflammatory, proliferative and remodeling phases. In the first stage, lasting up to 4 days after the injury (physiological healing), immune cell infiltration is observed (mainly neutrophils and macrophages) with subsequent secretion of proinflammatory cytokines (IL-1 and IL-6). The second, proliferative phase, lasting from the $4^{\text {th }}$ to the $14^{\text {th }}$ day after the injury, is focused on activation of keratinocytes, fibroblasts and endothelial cells. These cells are responsible for creating a scaffold in a healing wound and induction of neovascularization [5-9]. Additionally, various growth factors (IL-1, IL-6, GM-CSF, KGF, FGF, HGF, TGF- $\beta$ ) are secreted in vast amounts. The shift to the remodeling phase (from 14 days to 1 year after the injury) is performed through the involvement of macrophages, which change their phenotype from proinflammatory to "reparative". It is as-

Address for correspondence: Michał Pikuła MSc, PhD, Department of Clinical Immunology and Transplantology, Medical University of Gdansk, 7 Debinki St, 80-211 Gdansk, Poland, phone: +48 58349 15 92, fax: +48 58349 15 91, e-mail: pikula@gumed.edu.pl Received: 26.10.2017, accepted: 23.11.2017. 
sociated with the alternative activation of macrophages resulting from the pathway triggered by IL-4/IL-13 [10, 11].

Three major groups of factors can be distinguished in proper wound healing: factors relying on the operational technique, factors dependent on the patient, and external factors [5-9]. Among the crucial elements involving surgical methods influencing wound healing is ischemia of wound edges or lack of appropriate wound homeostasis during the surgery. Additional agents with negative feedback are imperfect stitches [6]. Aging, obesity, diseases such as diabetes, renal insufficiency, inherited and acquired immune deficiencies and prolonged use of steroids may significantly impact the process of wound healing [6]

Chemotherapy is known to impede the immunological mechanism, i.e. it leads to a decrease in white blood cell numbers. On the other hand, radiotherapy results in irradiation injury, which in the early phase is visible as inhibited circulation in the irradiated area [5, 12-17]. These side effects of chemo- and radiotherapy may be followed by a decrease in growth factors present at the postoperative site in patients with breast cancer, colorectal cancer or stomach cancer, treated with neoadjuvant therapy prior to surgery.

\section{Oncological treatment}

Neoadjuvant therapy, consisting of radio- and/or chemotherapy, can exert a negative impact on the wound healing process. Based on the malignancy development, patients undergo preoperative oncological treatment (neoadjuvant) or postoperative therapy (adjuvant) [18, 19]. The positive aspects of the concomitant therapy are the increased number of non-radical procedures, the extended 5-year survival rate of patients with malignancies and decreased incidence of local renewals after dissection [18]. Severe intraoperative conditions, disturbing appropriate recognition of anatomical structures, and prolonged wound healing are among negative conse- quences of combined radio- and chemotherapy. It may also result in a higher frequency of postoperative complications such as delayed wound healing in the form of separation and increased incidence of infections. As the reasons for improper wound healing, the worse wound blood supply or weaker regenerative potential of the postoperative field are considered. In order to minimize the side effects of preoperative radio- and chemotherapy, the best time for surgery was established at 4 to 6 weeks after neoadjuvant treatment. Nevertheless, this treatment protocol does not fully prevent wound healing disturbances, especially after radiotherapy [5, 12-17, 19].

Palliative wound treatment is also an important topic in oncology. Five-ten percent of cancer patients develop malignant fungating wounds at the end of life. This type of wound appears when advanced, metastatic or recurrent cancer infiltrates the skin and disrupts its integrity. Fungating wounds rarely heal and are characterized by bleeding, exudate, pain and odor caused by necrosis and microbial contamination $[20,21]$. These symptoms have to be controlled to improve patients' quality of life.

\section{Chemotherapy and wound healing}

Chemotherapy and chemotherapeutic agents have a lot of significant adverse effects leading to worsening of the patients' quality of life. It is known that widely used chemotherapeutic drugs may induce skin toxicity, manifested as skin rash, skin dryness and hyperpigmentation [22]. The mode of action of the majority of chemotherapeutics is based on inhibition of cell metabolism, cell division and angiogenesis. This way they block the pathways responsible for effective wound repair (Figure 1 A). Moreover, they interfere with replication, transcription and translation [23]. Most of the chemotherapeutic agents impede inflammation and delay or directly block angiogenesis. They influence cell migration to the wound and decrease extracellular matrix production. The reduced pro-
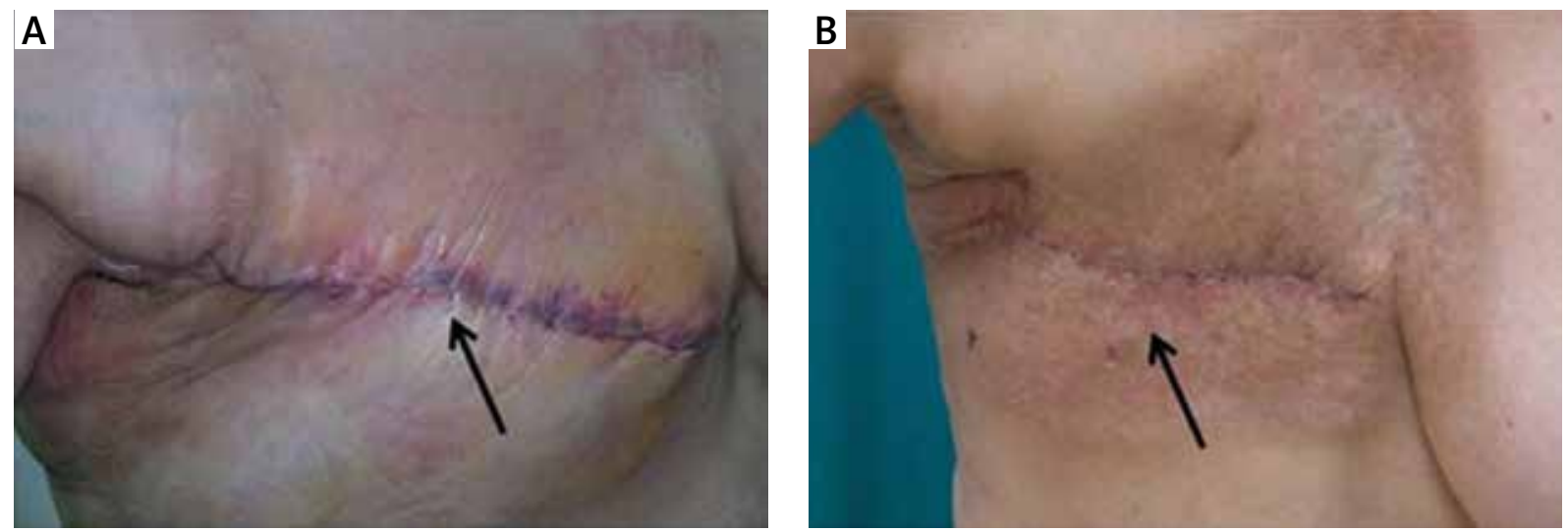

Figure 1. Delayed wound healing in patients after mastectomy undergoing preoperative chemotherapy (A - arrow indicates edema of the wound edges and redness) or postoperative radiotherapy (B - arrow shows delayed healing of wound edges and presence of radiation-induced skin damage in the irradiated field) 
duction of collagen is the result of the restrained fibroblast proliferation. Additionally, the rate of open wound closure is lowered [24]. Chemotherapy also affects and destroys patients' immune system, further hindering wound healing, and puts patients at risk of wound infections [23].

Chemotherapeutics such as cyclophosphamide and cisplatin block the cell cycle by alkylating DNA nucleotides, thus complicating wound healing. Cyclophosphamide attenuates the initial vasodilation and neovascularization in the proliferative phase of wound healing. Animal studies showed that its use in doses of $165-500 \mathrm{mg} / \mathrm{kg}$, but not below $100 \mathrm{mg} / \mathrm{kg}$, can result in decreased wound tensile strength. However, cyclophosphamide used in standard therapeutic doses (30-40 mg/kg) in human studies did not cause a delay in wound healing. Cisplatin also impacts the proliferative phase of wound healing in animals. Preoperative cisplatin treatment in rats inhibited neovascularization and reduced fibroblast and connective tissue proliferation [25].

Doxorubicin (Adriamycin) is cytotoxic to fibroblasts, thrombocytes, monocytes and leucocytes. It can inhibit mitosis of keratinocytes and decrease collagen synthesis. Additionally, it has a myelosuppressive effect on platelets and inflammatory cells [26]. Animal studies indicated its effect on delayed wound healing. Asmis et al. [27] showed that low cumulative doses of doxorubicin are responsible for protein S-glutathionylation in macrophages and impair their function in vivo in mice, which may be responsible for delayed wound healing. Gulcelik et al. [26] showed that the optimal timing for surgery after doxorubicin treatment in rats is before the $7^{\text {th }}$ or after the $35^{\text {th }}$ day. They also found that GM-CSF injected into the wound improves impaired wound healing in doxorubicin-treated rats [12].

\section{The impact of targeted therapies on skin}

Targeted drugs, inhibiting the growth and spread of tumor cells through blocking specific molecules involved in tumor progression, have become more widely used in cancer treatment. Theoretically, these drugs should be less toxic to healthy cells, but cutaneous reactions are quite common, due to the fact that some molecules drug targets - are also present in the skin (i.e. EGFR epidermal growth factor receptor) [28]. EGFR inhibitors (e.g. cetuximab, erlotinib) block not only their main target overexpressed in tumor cells, but also the receptors present in healthy keratinocytes in the stratum basale of the epidermis. The induced changes in the growth and migration of keratinocytes, combined with inflammation, result in xerosis and papulopustular skin rash [22]. The signaling pathways activated by EGFR are in charge of proliferation, differentiation, migration and keratinocyte survival. As a result of inhibition of these pathways, alternations in skin cells are visible. The inhibition of DNA synthesis and cell cycle restriction in G1 phase lead to growth disorders. Additionally, the processes of differ- entiation and keratinization are intensified. The EGFR inhibitors suppress the expression of EGFR and MAPK in stratum basale keratinocytes, but stimulate expression of p27, KRT1 and STAT3 responsible for a blockade of growth and premature cell differentiation. Therefore, adhesion seems to be encouraged, while the proper development of keratinocytes, observed as cell migration from the stratum basale to the stratum corneum, is disturbed. The consequences are visible as promotion of expression of genes inducing apoptosis and inflammation, followed by increased vascular permeability of epithelium and loss of skin natural barrier function $[29,30]$. Angiogenesis inhibitors (e.g. bevacizumab), acting by inhibition of the vascular endothelial growth factor (VEGF) pathway, can also affect wound healing. Anti-angiogenic activity may lead to decreased delivery of nutrients, oxygen and important cells to the wound side, which can cause surgical complications such as dehiscence, bleeding and infections. The available data suggest that the time of bevacizumab administration is crucial to avoid wound healing complications. The surgery should be performed 6-8 weeks after bevacizumab treatment, and this chemotherapeutic should not be taken for at least 28 days after surgery $[31,32]$.

\section{Radiotherapy and wound healing}

Many oncological patients undergoing radical radiotherapy suffer from acute skin toxicity. The group at risk consists of patients receiving the treatment to vulnerable areas of skin, such as sites where two skin surfaces are in contact, the epidermis is thin and smooth, or where skin integrity has already been disrupted (e.g. by surgery). The tissue regeneration in such irradiated skin areas may be severely impaired, causing prolonged wound healing (Figure 1 B). That may visibly impact the general healing process in oncological patients [33, 34].

Post-irradiation skin reactions can be divided according to the time of the appearance into early and late type. Early type reactions appear within a few weeks (up to 4) from the onset of radiotherapy. Late type skin reactions usually manifest a few months after the end of treatment and are the effect of fibroblast reactivity to irradiation $[34,35]$.

Another common complication of radiotherapy is osteoradionecrosis of the jaws. It is diagnosed in $5-15 \%$ of cases of radiotherapy for head and neck cancer, mostly in the first 3 years after treatment [36]. It is defined as a condition where irradiated bone is exposed through a wound in skin or mucosa and does not heal for 3-6 months without a residual or recurrent tumor [37]. The damage is not limited to bone and skin but also includes mucosa, fat, muscles and periosteum devastation [38].

Among the cells most sensitive to the effect of radiotherapy, due to their high proliferation and maturation index, are keratinocytes, hair follicle stem cells and 
melanocytes. Radiotherapy significantly interferes with proliferation and differentiation of endothelial cells, leading to the development of atypical cells and cutaneous vasculature.

Acute skin reactions are the result of the direct damage of the tissue, vessels and endothelial cells as well as the reduction and impairment of stem cells, local inflammation, apoptosis and necrosis of epidermal cells [39-41].

The toxic effect of radiotherapy is based on the direct ionization of DNA and the production of free radicals, such as reactive oxygen species (ROS) from water radiolysis. ROS cause the formation of dimers, base alterations and DNA double strand breaks, which finally lead to damage of stratum basale function. The disruption in the self-renewing property of the epidermis can be triggered even by the first fractionated dose of radiation, destroying a percentage of basal keratinocytes. The following and repeated exposures limit the time for tissue or DNA damage repair. Even though being continually destroyed with each dose of radiation treatment, the remaining keratinocytes are still stimulated to proliferate. The damage of stratum basale keratinocytes results in impairment of wound healing [39, 42-44]. Acutely irradiated skin is also affected with swelling and sloughing of epidermal cells and growth arrest [41].

Within a few hours after irradiation, the pro-inflammatory cascade is triggered and various inflammatory factors are released, including cytokines (IL-1, IL-3, IL-5, IL-6, TNF- $\alpha$ ), chemokines (IL-8, eotaxin, CCR receptor) and adhesive molecules (ICAM-1, V-CAM, E-selectin). Interleukin 1 is one of the proinflammatory cytokines produced by monocytes, macrophages as well as keratinocytes, fibroblasts and endothelial cells [45]. Its expression is induced directly after the first radiation dose and lasts up to 60 days after exposure. TNF- $\alpha$, another important proinflammatory factor, is engaged in both chronic and acute inflammation. This cytokine is secreted mainly by macrophages, but other immune cells are also capable of its production. Apart from proinflammatory properties, both cytokines - TNF- $\alpha$ and IL-1 - stimulate the secretion of matrix metalloproteinases (MMP), proteolytic enzymes degrading basal membrane end extracellular matrix. The local increase in TNF- $\alpha$ levels, accompanied by a higher concentration of IL-1, is a major symptom of acute inflammation [46, 47]. An increase in adhesion molecules expression, such as ICAM-1, enhances leukocyte interaction with the endothelium. The ICAM-1 acts as a promoter of adhesive interaction by binding integrins on the leucocyte surface, thus playing a pivotal role in migration and activation of $T$ cells. The irradiation-induced increase in ICAM-1 molecule expression was detected in long-term cultured HaCaT keratinocytes, HDFa fibroblast monolayer cells, a novel 3D skin model consisting of these cell lines grown in a special collagen sponge matrix, and skin biopsies from irradiated patients. Moreover, higher numbers of CD3+ T cells were noted in irradiated skin biopsies, which confirms the role of the ICAM-1 molecule in the leukocyte inflammatory migration process $[43,48]$. The overproduction of proinflammatory cytokines, due to exposure to radiation therapy, may lead to impairment of cell-to-cell and cell-to-extracellular matrix interaction, uncontrolled matrix decomposition and fibrosis. Additionally, NO synthesis was proved in animal models to be diminished in irradiated tissue. Nitric oxide, produced by macrophages and fibroblasts in wounds, accelerates healing through the induction of collagen decomposition. On the other hand, TNF- $\alpha$ and INF- $\gamma$, secreted by lymphocytes in irradiated wounds, prevent that decomposition. Hence, these two proinflammatory cytokines impede wound healing through induction of poor collagen decomposition [49, 50].

Chronic radiation dermatitis is a result of inflammation triggered by irradiation. This prolonged dermatitis is associated with overexpression of proinflammatory cytokines (TNF- $\alpha, I L-1, I L-6)$ and the activity of growth factors (TGF- $\beta$, PDGF and CTGF) promoting fibrosis through synthesis of extracellular matrix proteins and matrix metalloproteinases $[39,51]$. The increased level of TGF- $\beta$ in serum of irradiated patients correlates with higher risk of fibrotic tissue formation [52]. Transforming growth factor $\beta$ is an important growth factor controlling proliferative activity of various cell types. The mechanism of TGF- $\beta$ signaling is based on binding to the type I/II receptor complex, resulting in activation of Smad proteins [46]. It is widely known that in vitro fibroblast irradiation leads to TGF- $\beta$ secretion, enhancing differentiation of these cells. It is believed that premature differentiation is responsible for the accumulation of post-mitotic fibrocytes and increased synthesis and decomposition of extracellular collagen, an important factor of wound healing and fibrosis. Fibrocytes are 10 times more effective in collagen production than fibroblasts. Therefore, fibroblast differentiation induced by irradiation may significantly affect wound healing through fibrotic tissue formation and prolonged healing (recovery). Injury of the endothelium may induce inappropriate vascularization of irradiated skin, leading to an impaired blood supply [52-55]. Low levels of angiogenic factors (FGF, HGH, VEGF) in irradiated skin suggest that insufficiency in the production of these factors may be a culprit of disturbed angiogenesis [56]. Moreover, the prolonged inflammation and secretion of proinflammatory cytokines lead to leukocyte infiltration, causing other symptoms of skin inflammation such as atrophy of necrosis $[39,51]$.

\section{Cell therapies for chronic wound treatment}

Various modern dressings based on hydrogels, silver-coated membranes and allogenic skin sheets are currently used in wound healing. For example, palliative wounds can be managed by using special wound dress- 
ings - polyurethane foam, non-adhesive gelling dressing, antimicrobial dressings with activated charcoal or metronidazole gel. Hyperbaric oxygen therapy and negative pressure wound therapy are also in use [57].

Contemporary regenerative medicine and tissue engineering are behind the development of more successful therapies of different kinds of wounds. Scientists are now focused on cell application in treatment of chronic wounds. These cells may be transplanted as a cell suspension directly injected onto the wound, combined with a proper carrier or a complex 3D skin scaffold $[4,58]$.

For the sake of safety and long-term therapeutic effects, autologous transplantations outnumber allogeneic transplantations from other healthy donors. The longest clinical observations are made on in vitro expanded keratinocytes and epidermal stem cell transplantations [59]. Epidermal stem cells are localized mainly in the stratum basale and the bulge region of the hair follicle. It is believed that during physiological epidermal renewal, only primarily activated stratum basale cells are engaged in this process. In the course of wound healing, stem cells localized in different skin regions are stimulated, e.g. the bulge region cells. These cell actively migrate to the epithelial area and undergo terminal differentiation [60, 61]. It explains the accelerated wound healing in hairy skin [62].

Currently, stem cells can be easily isolated from small skin fragments $\left(0.5-1.0 \mathrm{~cm}^{2}\right)$ and successfully cultured and multiplied in vitro in xeno-free media (Figure $2 \mathrm{~A}$ ). These cells may be subsequently applied as a suspension (e.g. in fibrin glue), in the form of epidermis or an engineered skin substitute (ESS), constituting effective treatment of chronic wounds or skin loss [63]. Transplanted cells constitute a natural skin barrier, and at the same time are an important source of growth factors facilitating wound healing [64].

Bone marrow constitutes a rich source of hematopoietic and mesenchymal stem cells (HSCs and MSCs, respectively). Other types of progenitor cells might be lo- calized in bone marrow and are mobilized to the periphery in response to various traumas. Stem cells, particularly HSCS, participate in wound healing with extensive inflammation $[65,66]$. Their recruitment is dependent on the secretion of cytokines and growth factors (SDF-1, VEGF, HGF, angiopoietin) from injured tissues [65, 67]. Data obtained in human studies showed that bone marrow cells are directly engaged in skin regeneration. It is presumably related to the MCSs' ability to differentiate into fibroblasts and keratinocytes [68]. Bone marrow can also be an abundant source of endothelial cell precursors, released to the circulation under stimulation of SDF, VEGF, GM-CSF and such unspecific factors as hypoxia or burns. Endothelial precursors play a substantial role in extensive wound healing by induction of new vessel formation [69]. The present-day data describe numerous clinical trials applying stem/progenitor cells of bone marrow origin (HSCS, MSCS), as well as mobilization of these cells from bone marrow through growth factors (e.g. GM-CSF) [4, 70].

In the past decade human adipose tissue has been identified as a source of multipotent stem cells (Figure 2 B). Adipose-derived stem cells (ASCs) proved to have significant biological properties and considerable therapeutic potential [71]. It seems that ASCs, in their physiological state, remain rather quiescent, but under stimulation (such as a wound, a transplant, or in vitro culture) exert pro-regenerative capabilities. Transplanted ASCs participate in the healing process of both acute and chronic wounds, simultaneously preventing hypertrophic scars and keloids [72, 73]. One of the major functions of ASCS is the stimulation of angiogenesis by differentiation into endothelial cells and activation of differentiated endotheliocytes. These cells can also transform into fibroblasts and even, under specific conditions, into keratinocytes [74-76]. Exogenic ASCs mobilize endogenic stem cells, particularly the epidermal stem cells located in the bulge region. This mechanism of action is based on various
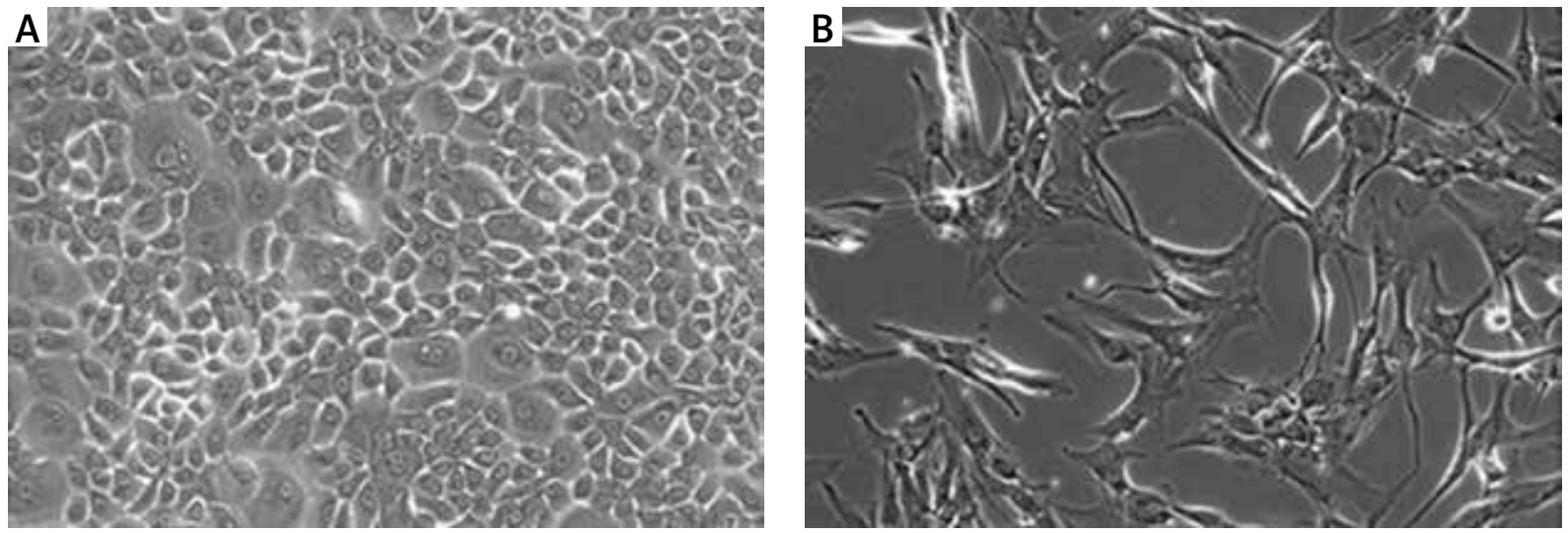

Figure 2. Examples of cells with potential application in oncological wound treatment ( $\mathbf{A}$ - human primary keratinocytes, $2^{\text {nd }}$ passage; $B$ - human ASCs, $2^{\text {nd }}$ passage) 
growth factor production, including FGF, HGF, TGF- $\beta$ and VEGF. Other vital features of ASCs are their immunosuppressive and anti-inflammatory properties, important in treatment of chronic wounds accompanied by prolonged inflammation [72]. The activity of ASCs relies on microenvironmental conditions and accelerates in hypoxia or under stimulation of growth factors. Due to the high metabolic rate and large amounts of secreted in vitro growth factors, ASCs' culture medium is being tested as a potential treatment in skin inflammation. ASCs are a promising tool for treatment of chronic (e.g. ulcers) and oncological wounds [71]. Rigotti et al. [77] in a pilot clinical study in humans showed that injection of autologous lipopaspirates, which contain ASCs, can be effective in treating late side effects of radiotherapy. Improvement was seen in all patients and ASCs application induced damaged tissue transformation into normal tissue. The beneficial effect was prominent in patients suffering from cutaneous ulcers and even osteoradionecrosis. Despite nearly a decade of investigations, there is no agreement on ASCs' effect on tumor growth and safety of this therapy in oncological patients. Their oncological safety should be carefully considered before they become commonly used [78].

Stem cells also seem to be a promising candidate for osteoradionecrosis treatment. Mendonça et al. [38] reported use of a mixed population of autologous cultured bone marrow-derived stem and progenitor cells as a novel regenerative procedure in three patients with craniofacial diseases, including one diagnosed with a severely fractured mandible as a result of advanced osteoradionecrosis. In this case the necrotic tissue was excised, a mandibular reconstruction plate was placed, the cells were inoculated into the skin, muscle, areas adjacent to the facial nerve, and the necrosed vascular stumps, and the wound was closed. The procedure resulted in osteogenesis, angiogenesis, arteriogenesis, and skin and nerve regeneration. Most of the lost facial tissues and functions were restored.

Hyperbaric oxygen therapy ( $\mathrm{HBO}$ ) is used in treatment of different wounds including those caused by radiotherapy. It is combined with standard wound care techniques [49]. This therapy is generally safe and well tolerated, but side effects can occur when oxygen is used in high doses or for longer than recommended. Its use during surgical procedures promotes wound healing and reduces pain [79]. Thom et al. found that HBO treatment mobilizes stem/progenitor cells (SPCs) in healthy people and patients after radiotherapy for head and neck tumors [80]. Animal studies show promising results of HBO combination with MSCs cell therapy in repair of traumatic brain injury, bone repair and spinal cord rehabilitation, which suggests that it may also be useful in wound healing promotion [81-83]. However, there are no well-controlled human studies indicating the efficiency of such therapy and, taking into consideration the sensitivity of transplanted cells, it would have to be used with caution.

\section{Conclusions}

Chemotherapy and/or radiotherapy is often the therapy of choice for treating various types of cancers. This type of treatment may lead to delayed wound healing and worsening of patients' quality of life. Cellular therapies seem to be a promising tool in treatment of wounds caused by chemotherapy or radiotherapy, but their safety in oncological patients needs to be taken into consideration.

\section{Acknowledgments}

Milena Deptuła and Jacek Zieliński contributed equally to this work.

This work was supported by the funds of the Polish National Science Centre granted to Michał Pikuła based on decision no. Dec-2011/03/D/N25/00555 and the National Centre for Research and Development, grant no. STRATEGMED1 /235077/9/NCBR/2014.

\section{Conflict of interest}

The authors declare no conflict of interest.

\section{References}

1. Ferlay J, Soerjomataram I, Dikshit R, et al. Cancer incidence and mortality worldwide: sources, methods and major patterns in GLOBOCAN 2012. Int J Cancer 2015; 136: E359-86.

2. Torre LA, Bray F, Siegel RL, et al. Global cancer statistics, 2012. CA Cancer J Clin 2015; 65: 87-108.

3. Torre LA, Siegel RL, Ward EM, Jemal A. Global cancer incidence and mortality rates and trends - an update. Cancer Epidemiol Biomarkers Prev 2016; 25: 16-27.

4. Pikuła M, Langa P, Kosikowska P, Trzonkowski P. Stem cells and growth factors in wound healing. Postepy Hig Med Dosw 2015; 69: 874-85.

5. Bose D, Meric-Bernstam F, Hofstetter W, et al. Vascular endothelial growth factor targeted therapy in the perioperative setting: implications for patient care. Lancet Oncol 2010; 11: 373-82.

6. Cross KJ, Mustoe TA. Growth factors in wound healing. Surg Clin North Am 2003; 83: 531-45.

7. Olszewski WL. Gojenie się ran. In: Podstawy chirurgii. Podręcznik dla lekarzy specjalizujących się w chirurgii ogólnej. Szmid J, Kużdżał J, Gruca Z, et al. (eds). Wydawnictwo MP, Kraków 2010; 231-60.

8. Marjanovic G, Hopt UT. Physiology of anastomotic healing. Chirurg 2011; 82: 41-7.

9. Pollack SV. The wound healing process. Clin Dermatol 1984; 2: 8-16.

10. Koh TJ, DiPietro LA. Inflammation and wound healing: the role of the macrophage. Expert Rev Mol Med 2011; 13: e23.

11. Daley JM, Brancato SK, Thomay AA, et al. The phenotype of murine wound macrophages. J Leukoc Biol 2010; 87: 59-67.

12. Gulcelik MA, Dinc S, Dinc M, et al. Local granulocyte-macrophage colony-stimulating factor improves incisional wound healing in adriamycin-treated rats. Surg Today 2006; 36: 47-51.

13. Uzunkoy A, Bolukbas C, Horoz M, et al. The optimal starting time of postoperative intraperitoneal mitomycin-C therapy 
with preserved intestinal wound healing. BMC Cancer 2005; 5: 31.

14. Kolb BA, Buller RE, Connor JP, et al. Effects of early postoperative chemotherapy on wound healing. Obstet Gynecol 1992; 79: 988-92.

15. Dormand EL, Banwell PE, Goodacre TE. Radiotherapy and wound healing. Int Wound J 2005; 2: 112-27.

16. Devalia HL, Mansfield L. Radiotherapy and wound healing. Int Wound J 2008; 5: 40-4.

17. Ozbek N, Guneren E, Yildiz L, et al. The effect of pre-operative conventional and hyperfractionated radiotherapy schedules on wound healing and tensile strength in rats: an experimental study. Int J Oral Maxillofac Surg 2005; 34: 185-92.

18. Mendelsohn FA, Divino CM, Reis ED, Kerstein MD. Wound care after radiation therapy. Adv Skin Wound Care 2002; 15: 216-24.

19. Drake DB, Oishi SN. Wound healing considerations in chemotherapy and radiation therapy. Clin Plast Surg 1995; 22: 31-7.

20. Langemo DK, Anderson J, Hanson D, et al. Managing fungating wounds. Adv Skin Wound Care 2007; 20: 312-4.

21. Merz T, Klein C, Uebach B, et al. Fungating wounds - multidimensional challenge in palliative care. Breast Care 2011; 6: 21-4.

22. Fabbrocini G, Cameli N, Romano MC, et al. Chemotherapy and skin reactions. J Exp Clin Cancer Res 2012; 31: 50.

23. Guo S, DiPietro LA. Factors affecting wound healing. J Dent Res 2010; 89: 219-29.

24. Franz MG, Steed DL, Robson MC. Optimizing healing of the acute wound by minimizing complications. Curr Probl Surg 2007; 44: 691-763.

25. Payne WG, Naidu DK, Wheeler CK, et al. Wound healing in patients with cancer. Eplasty 2008; 8: e9.

26. Gulcelik MA, Dinc S, Gulcelik NE, et al. Optimal timing for surgery after adriamcin treatment in rats. Surg Today 2004; 34: 1031-4.

27. Asmis R, Qiao M, Rossi RR, et al. Adriamycin promotes macrophage dysphunction in mice. Free Radic Biol Med 2006; 41: 165-74.

28. Reyes-Habito CM, Roh EK. Cutaneous reactions to chemotherapeutic drugs and targeted therapies for cancer: part II. Targeted therapies. J Am Acad Dermatol 2014; 71: 217.e1-11.

29. Kryński J, Kamińska GG, Kamińska-Winciorek G. Leczenie reakcji skórnych występujących podczas terapii inhibitorami receptora nabłonkowego czynnika wzrostu u pacjentów z rakiem jelita grubego. Onkol Prakt Klin 2010; 6: 318-32.

30. Sobańska K, Szałek E, Grześkowiak E. Skórne działania niepożądane drobnocząsteczkowych inhibitorów kinazy tyrozynowej receptora naskórkowego czynnika wzrostu EGFR (ang. epidermal growth factor receptor). Farm Współ 2013; 6: 33-40.

31. Macdonald JB, Macdonald B, Golitz LE, et al. Cutaneous adverse effects of targeted therapies: Part I: Inhibitors of the cellular membrane. J Am Acad Dermatol 2015; 72: 203-18.

32. Aderson K, Hamm RL. Factors that impair wound healing. Am Coll Clin Wound Spec 2012; 4: 84-91.

33. Kumar S, Juresic E, Barton M, Shafiq J. Management of skin toxicity during radiation therapy: a review of the evidence. J Med Imag Radiat Oncol 2010; 54: 264-79.

34. McQuestion M. Evidence-based skin care management in radiation therapy. Semin Oncol Nurs 2006; 22: 163-73.
35. Wiśniewski M, Graczyk M, Szpinda M, BrzozowskaMańkowska S. Popromienne zapalenie skóry - zasady postępowania. Med Pal Prakt 2013; 7: 41-5.

36. Rice N, Polyzois I, Ekanayake K, et al. The management of osteoradionecrosis of the jaws - a review. Surgeon 2015; 13 : 101-9.

37. O’Dell K, Sinha U. Osteoradionecrosis. Oral Maxillofac Surg Clin North Am 2011; 23: 455-64.

38. Mendonça JJ, Juiz-Lopez P. Regenerative facial reconstruction of terminal stage osteoradionecrosis and other advanced craniofacial diseases with adult cultured stem and progenitor cells. Plast Reconstr Surg 2010; 126: 1699-709.

39. Bray FN, Simmons BJ, Wolfson AH, Nouri K. Acute and chronic cutaneous reactions to ionizing radiation therapy. Dermatol Ther (Heidelb) 2016; 6: 185-206.

40. Hegedus F, Mathew LM, Schwartz RA. Radiation dermatitis: an overview. Int J Dermatol 2017; 56: 909-14.

41. Hymes SR, Strom EA, Fife C. Radiation dermatitis: clinical presentation, pathophysiology, and treatment 2006. J Am Acad Dermatol 2006; 54: 28-4.

42. Córdoba EE, Abba MC, Lacunza E, et al. Polymorphic variants in oxidative stress genes and acute toxicity in breast cancer patients receiving radiotherapy. Cancer Res Treat 2016; 48: 948-54.

43. Kodiyan J, Amber KT. A review of the use of topical calendula in the prevention and treatment of radiotherapy-induced skin reactions. Antioxidants 2015; 4: 293-303.

44. Ryan JL. Ionizing radiation: the good, the bad, and the ugly. J Invest Dermatol 2012; 132: 985-93.

45. Müller K, Meineke V. Radiation-induced alterations in cytokine production by skin cells. Exp Hematol 2007; 35: 96-104.

46. Kim JH, Jenrow KA, Brown SL. Mechanisms of radiation-induced normal tissue toxicity and implications for future clinical trials. Radiat Oncol J 2014; 32: 103-15.

47. Janko M, Ontiveros F, Fitzgerald TJ, et al. IL-1 generated subsequent to radiation-induced tissue injury contributes to the pathogenesis of radiodermatitis. Radiat Res 2012; 178: 166-72.

48. Müller K, Köhn FM, Port M, et al. Intercellular adhesion molecule-1: a consistent inflammatory marker of the cutaneous radiation reaction both in vitro and in vivo. Br J Dermatol 2006; 155: 670-9.

49. Haubner F, Ohmann E, Pohl F, et al. Wound healing after radiation therapy: review of the literature. Radiat Oncol 2012; 7: 162-70.

50. Dormand EL, Banwell PE, Goodacre TE. Radiotherapy and wound healing. Int Wound J 2005; 2: 112-27.

51. Spałek M. Chronic radiation-induced dermatitis: challenges and solutions. Clin Cosmet Investig Dermatol 2016; 9: 473-82

52. Pohlers D, Brenmoehl J, Löffler I, et al. TGF-beta and fibrosis in different organs - molecular pathway imprints. Biochim Biophys Acta 2009; 1792: 746-56.

53. Akudugu JM, Bell RS, Catton C, et al. Clonogenic survival and cytokinesis-blocked binucleation of skin fibroblasts and normal tissue complications in soft tissue sarcoma patients treated with preoperative radiotherapy. Radiother Oncol 2004; 72: 103-12.

54. Akudugu JM, Bell RS, Catton C, et al. Wound healing morbidity in STS patients treated with preoperative radiotherapy in relation to in vitro skin fibroblast radiosensitivity, proliferative capacity and TGF-beta activity. Radiother Oncol 2006; 78: 17-26. 
55. Kumar S, Kolozsvary A, Kohl R, et al. Radiation-induced skin injury in the animal model of scleroderma: implications for post-radiotherapy fibrosis. Radiat Oncol 2008; 3: 40.

56. Goessler UR, Bugert P, Kassner S, et al. In vitro analysis of radiation-induced dermal wounds. Otolaryngol Head Neck Surg 2010; 142: 845-50.

57. Chrisman CA. Care of chronic wounds in palliative care and end-of-life patients. Int Wound J 2010; 7: 214-35.

58. Horch RE, Kopp J, Kneser U, et at. Tissue engineering of cultured skin substitutes. J Cell Mol Med 2005; 9: 592-608.

59. Chen M, Przyborowski M, Berthiaume F. Stem cells for skin tissue engineering and wound healing. Crit Rev Biomedical Eng 2009; 37: 399-421.

60. Levy V, Lindon C, Zheng Y, et al. Epidermal stem cells arise from the hair follicle after wounding. FASEB I 2007; 21: 1358-66.

61. Morris RJ, Liu Y, Marles L, et al. Capturing and profiling adult hair follicle stem cells. Nat Biotech 2004; 22: 411-7.

62. Lau K, Paus R, Tiede S, et al. Exploring the role of stem cells in cutaneous wound healing. Exp Dermatol 2009; 18: 921-33.

63. Pikuła M, Kondej K, Jaśkiewicz J, et at. Flow cytometric sorting and analysis of human epidermal stem cell candidates. Cell Biol Int 2010; 34: 911-5.

64. Pikuła M, Trzonkowski P. Biology of epidermal stem cells: impact on medicine. Postepy Hig Med Dosw 2009; 15: 449-56.

65. Staniszewska M, Słuczanowska-Głabowska S, Drukała J. Stem cells and skin regeneration. Folia Histochem Cytobiol 2011; 49: 375-80.

66. Ennis WJ, Sui A, Bartholomew A. Stem cells and healing: impact on inflammation. Adv Wound Care (New Rochelle) 2013; 2: 369-78.

67. Atala A, Lanza R, Thomson JA, Nerem R. Principles of Regenerative Medicine. Elsevier, New York 2011.

68. Nair RP, Krishnan LK. Identification of p63+ keratinocyte progenitor cells in circulation and their matrix-directed differentiation to epithelial cells. Stem Cell Res Ther 2013; 4: 38.

69. Urbich C, Dimmeler S. Endothelial progenitor cells: characterization and role in vascular biology. Circ Res 2004; 95: 343-53.

70. Chi YF, Chai JK, Luo HM. Safety of recombinant human granulocyte-macrophage colony-stimulating factor in healing pediatric severe burns. Genet Mol Res 2015; 14: 2735-41.

71. Pikuła M, Marek-Trzonkowska N, Wardowska A, et al. Adipose tissue-derived stem cells in clinical applications. Expert Opin Biol Ther 2013; 13: 1357-70.

72. Cherubino M, Rubin JP, Miljkovic N, et al. Adipose-derived stem cells for wound healing applications. Ann Plast Surg 2011; 66: 210-5.

73. Ebrahimian TG, Pouzoulet F, Squiban C, et al. Cell therapy based on adipose tissue-derived stromal cells promotes physiological and pathological wound healing. Arterioscler Thromb Vasc Biol 2009; 29: 503-10.

74. Auxenfans C, Lequeux C, Perrusel E, et al. Adipose-derived stem cells (ASCs) as a source of endothelial cells in the reconstruction of endothelialized skin equivalents. J Tissue Eng Regen Med 2012; 6: 512-8.

75. Deveza L, Choi J, Imanbayev G, Yang F. Paracrine release from nonviral engineered adipose-derived stem cells promotes endothelial cell survival and migration in vitro. Stem Cells Dev 2013; 22: 483-91.

76. Lee SH, Jin SY, Song JS, et al. Paracrine effects of adipose-derived stem cells on keratinocytes and dermal fibroblasts. Ann Dermatol 2012; 24: 136-43.
77. Rigotti G, Marchi A, Galie M, et al. Clinical treatment of radiotherapy tissue damage by lipoaspirate transplant: a healing process mediated by adipose-derived adult stem cells. Plast Reconstr Surg 2007; 119: 1409-22.

78. Alperovich M, Lee ZH, Friedlander PL, et al. Adipose stem cell therapy in cancer reconstruction: a critical review. Ann Plast Surg 2014; 73: S114-7.

79. Stępień K, Ostrowski RP, Matyja E. Hyperbaric oxygen as an adjunctive therapy in treatment of malignancies, including brain tumours. Med Oncol 2016; 33: 101.

80. Thom SR, Bhopale VM, Velazquez OC, et al. Stem cell mobilization by hyperbaric oxygen. Am J Physiol Heart Circ Physiol 2006; 290: H1378-86.

81. Zhou H, Liu Z, Liu X, Chen Q. Umbilical cord-derived mesenchymal stem cell transplantation combined with hyperbaric oxygen treatment for repair of traumatic brain injury. Neural Regen Res 2016; 11: 107-13.

82. Grassmann JP, Schneppendahl J, Sager M, et al. The effect of bone marrow concentrate and hyperbaric oxygen therapy on bone repair. J Mater Sci Mater Med 2015; 26: 5331.

83. Geng CK, Cao HH, Ying X, Yu HL. Effect of mesenchymal stem cells transplantation combining with hyperbaric oxygen therapy on rehabilitation of rat spinal cord injury. Asian Pac J Trop Med 2015; 8: 468-73. 